\title{
PENGAMATAN JENIS-JENIS PLANKTON DI PERAIRAN SUNGAI MUSI, SUMATERA SELATAN
}

\author{
Syamsul Bahri') \\ 1) Teknisi Litkayasa pada Balai Riset Perikanan Perairan Umum, Mariana-Palembang \\ Teregristasi I tanggal: 19 Mei 2005; Diterima setelah perbaikan tanggal: 20 Oktober 2005; \\ Disetujui terbit tanggal: 20 Desember 2005
}

\section{PENDAHULUAN}

Plankton adalah organisme renik perairan baik sebagai produsen primer maupun sebagai produsen sekunder (Wetzel, 1975). Kesuburan suatu perairan dapat dilihat dari plankton, karena dapat menggambarkan tingkat produktivitas dari perairan tersebut. Keberadaan plankton di suatu perairan sangat berpengaruh terhadap kelangsungan hidup ikan di perairan tersebut terutama bagi ikan pemakan plankton. Untuk itu, perlu dilakukan pengamatan kelimpahan plankton di perairan Sungai Musi, Sumatera Selatan.

Sungai Musi dengan ke-9 anak sungai merupakan sistem sungai yang kompleks, terdiri atas bagian yang berarus deras di kaki gunung, dataran rendah, dan pasang surut (air tawar) serta bagian air payau (kuala atau estuari). Aliran air melalui beberapa tata guna lahan yang beragam, dimulai dari kawasan hutan lindung dibagian hulu, kebun campuran, lahan pertanian, lahan permukiman, kawasan industri, dan lahan hutan mangrove di bagian hilir. Dengan banyak aktivitas penggunaan lahan di tepian perairan Sungai Musi tersebut langsung ataupun tidak langsung dapat memberikan dampak negatif terhadap kualitas perairan. Kualitas perairan akan menentukan kelimpahan dan komposisi jenis plankton. Tulisan ini menyajikan hasil pengamatan jenis-jenis plankton di perairan Sungai Musi, Sumatera Selatan.

\section{POKOK BAHASAN}

\section{BAHAN DAN ALAT}

Bahan terdiri atas plankton net No.25, botol vial $25 \mathrm{ml}$, formalin, dan ember plastik volume $10 \mathrm{l}$.

Alat terdiri atas mikroskop dan sedwick rafter.

Pengambilan contoh plankton dilakukan pada bulan Juni sampai dengan Juli tahun 2002 mewakili musim kemarau dan bulan September sampai dengan Nopember 2002 mewakili musim penghujan. Stasiun pengambilan contoh berjumlah 15 lokasi yang mewakili Sungai Musi bagaian hulu, tengah, dan hilir.

Pengumpulan plankton dilakukan dengan cara menyaring air contoh $50 \mathrm{I} \mathrm{ke} \mathrm{dalam} \mathrm{plankton} \mathrm{net} \mathrm{No.25}$ yang ditampung dalam botol vial bervolume $25 \mathrm{ml}$, selanjutnya diawetkan dengan larutan formalin $4 \%$. Pengamatan plankton dilakukan di laboratorium hidrobiologi Balai Riset Perikanan Perairan umum, Mariana-Palembang dengan menggunakan buku petunjuk APHA (1981); Penak (1978). Jenis-jenis plankton diidentifikasikan dan dihitung secara lintasan berdasarkan pada metode Sedwick Rafter (APHA, 1981), yaitu:

$$
\begin{aligned}
& \text { Jumlah per ml : } \underline{\text { Cx1000 mm3 }} \text {....................... } \\
& \text { LxDxWXS }
\end{aligned}
$$

di mana:

$$
\begin{aligned}
& C=\text { jumlah organisme yang dihitung } \\
& L=\text { panjang setiap lintasan }(50 \mathrm{~mm}) \\
& D=\text { kedalaman Sedwick-Rafter }(1 \mathrm{~mm}) \\
& W=\text { lebar lintasan }(1 \mathrm{~mm}) \\
& S=\text { jumlah lintasan yang dihitung (4 lintasan) }
\end{aligned}
$$

\section{HASIL PENGAMATAN}

Kepadatan populasi dan jenis-jenis plankton yang teridentifikasi di perairan Sungai Musi, Sumatera Selatan pada tahun 2002 (sel per I) dapat dilihat pada Tabel 1 sampai dengan 4. Pada Tabel 1 jenis-jenis plankton pada bulan Juni 2002 terdapat 4 kelas Phytoplankton dan 2 kelas Zooplankton. Jenis Phytoplankton dari kelas Bacillariophyceae (10 jenis) yaitu 2.711 sel per I, kelas Chlorophyceae (17 jenis) yaitu $3.998 \mathrm{sel}$ per I, kelas Cyanophyceae (1 jenis) yaitu 578 sel per I dan kelas Euglenaphyceae (2 jenis) yaitu k 311 sel per I. Daerah penyebaran di bagian hulu, tengah, dan hilir terdapat 5 jenis, di bagian tengah dan hilir terdapat 2 jenis, dan di bagian hulu dan tengah terdapat 2 jenis serta di bagian hilir terdapat 1 jenis. Sedangkan jenis Zooplankton dari kelas Rotifera (2 jenis) yaitu 400 ind. per I dan kelas Copepoda (1 jenis) yaitu 400 ind. per I. Sedangkan penyebaran sama-sama di bagian tengah dan hilir.

Pada Tabel 2 jenis-jenis plankton yang teridentifikasi pada bulan Juli 2002 (sel per I), terdapat 6 kelas Phytoplankton dan 2 kelas Zooplankton. Jenis Phytoplankton dari kelas Bacillariophyceae (10 jenis) yaitu 2.349 sel per I, kelas Chlorophyceae (24 jenis) yaitu 3.777 sel per I, kelas Cyanophyceae (8 jenis) yaitu 706 sel per I, kelas Rhodophyceae ( 2 jenis) yaitu 88 sel per I, kelas Euglenaphyceae (1 jenis) yaitu 178 sel per I dan kelas Xantrophyceae ( 1 jenis) yaitu 44 sel per liter. Daerah penyebaran di bagian hulu, 
tengah dan hilir terdapat 4 jenis, di bagian hulu terdapat 1 jenis, di bagian tengah terdapat 2 jenis, dan di bagian tengah dan hilir terdapat 1 jenis. Dari kelas Chlorophyceae, di bagian hulu, tengah, dan hilir terdapat 6 jenis, di bagian tengah terdapat 6 jenis, di bagian hulu dan tengah terdapat 1 jenis, di bagian hulu terdapat 1 jenis, di bagian tengah dan hilir terdapat 6 jenis dan di bagian hilir terdapat 4 jenis. Dari kelas Cyanophyceae, di bagian hulu, tengah, dan hilir terdapat 1 jenis, di bagian tengah terdapat 4 jenis, di bagian tengah dan hilir terdapat 1 jenis, di bagian hilir terdapat 2 jenis. Dari kelas Rodophyceae, terdapat 2 jenis sama-sama di bagian tengah. Dari kelas Euglenaphyceae, di bagian tengah dan hilir terdapat 1 jenis. Dari kelas Xantrophyceae, di bagian hulu terdapat 1 jenis. Sedangkan jenis Zooplankton dari kelas Rotifera, di bagian tengah terdapat 3 jenis, di bagian tengah dan hilir terdapat 3 jenis, di bagian hilir terdapat 2 jenis. Dari kelas Copepoda, di bagian hulu terdapat 1 jenis, di bagian tengah terdapat 1 jenis, di bagian tengah dan hilir terdapat 1 jenis, dan di bagian hilir terdapat 1 jenis.

Pada Tabel 3 jenis-jenis plankton yang teridentifikasi pada bulan September 2002 (sel per I), terdapat 4 kelas Phytoplankton dan 3 kelas Zooplankton. Jenis Phytoplankton dari kelas Bacillariophyceae (7 jenis) yaitu 1.286 sel per I, kelas Chlorophyceae (17 jenis) yaitu 3.827 sel per I, kelas Cyanophyceae (4 jenis) yaitu 755 sel per I, dan kelas Rhodophyceae (1 jenis) yaitu 44 sel per I. Daerah penyebaran di bagian hulu, tengah, dan hilir terdapat 2 jenis, di bagian hulu dan tengah terdapat 2 jenis, di bagian hulu terdapat 2 jenis, di bagian tengah dan hilir terdapat 1 jenis. Dari kelas Chlorophyceae, di bagian hulu, tengah, dan hilir terdapat 5 jenis, di bagian hulu terdapat 2 jenis, di bagian tengah terdapat 2 jenis, di bagian hulu dan tengah terdapat 1 jenis, di bagian tengah dan hilir terdapat 4 jenis, di bagian hulu terdapat 1 jenis, di bagian hilir terdapat 1 jenis dan di bagian hulu dan hilir terdapat 1 jenis. Dari kelas Cyanophyceae, di bagian hulu dan hilir terdapat 2 jenis, di bagian tengah dan hilir terdapat 1 jenis, di bagian hilir terdapat 1 jenis. Dari kelas Rodophyceae, di bagian hulu terdapat 1 jenis. Sedangkan jenis Zooplankton dari kelas Rotifera, di bagian tengah dan hilir terdapat 3 jenis, di bagian tengah terdapat 1 jenis. Dari kelas Copepoda, di bagian hilir terdapat 2 jenis. Dari kelas Clodocera, di bagian tengah dan hilir terdapat 1 jenis.

Pada Tabel 4 jenis-jenis plankton yang teridentifikasi pada bulan Nopember 2002 (sel per I), terdapat 3 kelas Phytoplankton dan 2 kelas Zooplankton. Jenis Phytoplankton dari kelas Bacillariophyceae (5 jenis) yaitu 1.598 sel per li, kelas Chlorophyceae (16 jenis) yaitu 2.483 sel per I, kelas Cyanophyceae (3 jenis) yaitu 265 sel per I. Daerah penyebaran dari kelas Bacillariophyceae di bagian hulu, tengah, dan hilir terdapat 3 jenis, di bagian hulu dan tengah terdapat 1 jenis, di bagian hilir terdapat 1 jenis. Dari kelas Chlorophyceae di bagian hulu, tengah, dan hilir terdapat 1 jenis, di bagian hulu dan tengah terdapat 3 jenis, di bagian tengah terdapat 4 jenis, di bagian hulu terdapat 1 jenis, di bagian tengah dan hilir terdapat 2 jenis dan di bagian hilir terdapat 5 jenis. Sedangkan jenis Zooplankton dari kelas Rotifera (7 jenis) yaitu 885 ind. per I dan dari kelas Copepoda (2 jenis) yaitu 721 ind. per I. Daerah penyebaran dari kelas Rotifera di bagian hulu dan tengah terdapat 1 jenis, di bagian tengah terdapat 1 jenis, di bagian tengah dan hilir terdapat 2 jenis, dan di bagian hulu dan hilir terdapat 1 jenis, di bagian hilir terdapat 2 jenis. Dan dari kelas Copepoda di bagian hulu, tengah, dan hilir terdapat 1 jenis, di bagian hilir terdapat 1 jenis. 
Tabel 1. Jenis-jenis plankton yang teridentifikasi di perairan Sungai Musi, bulan Juni 2002 (sel per ind. perl)

\begin{tabular}{|c|c|c|c|}
\hline No. & Jenis plankton & Jumlah sel per ind. per I & Daerah penyebaran \\
\hline \multicolumn{4}{|c|}{ A. Phytoplankton } \\
\hline \multicolumn{4}{|c|}{ I. Bacillariophyceae } \\
\hline 1. & Synedra & 355 & Hulu, tengah, dan hilir \\
\hline 2. & Navicula & 133 & Tengah dan hilir \\
\hline 3. & Tabellaria & 355 & Hulu dan tengah \\
\hline 4. & Diatoma & 223 & Hulu, tengah, dan hilir \\
\hline 5. & Stephanodiscuss & 312 & Hulu, tengah, dan hilir \\
\hline 6. & Flagillaria & 400 & Hulu, tengah, dan hilir \\
\hline 7. & Surrirella & 578 & Hulu, tengah, dan hilir \\
\hline 8. & Cyclotella & 223 & Tengah dan hilir \\
\hline 9. & Gyrosigma & 44 & Hilir \\
\hline 10. & Melosira & 88 & Hulu dan tengah \\
\hline \multicolumn{4}{|c|}{ II. Chlorophyceae } \\
\hline 1. & Chlororella & 444 & Hulu, tengah, dan hilir \\
\hline 2. & Drapalnaldia & 178 & Tengah dan hilir \\
\hline 3. & Ulothrix & 489 & Hulu, tengah, dan hilir \\
\hline 4. & Closterium & 266 & Hulu, tengah, dan hilir \\
\hline 5. & Volvox & 312 & Hulu, tengah, dan hilir \\
\hline 6. & Chlorococcum & 266 & Tengah dan hilir \\
\hline 7. & Pediastrum & 266 & Hulu, tengah, dan hilir \\
\hline 8. & Zygnema & 222 & Hulu, tengah, dan hilir \\
\hline 9. & Staurastrum & 133 & Tengah dan hilir \\
\hline 10. & Sphaerocystis & 133 & Tengah dan hilir \\
\hline 11. & Micrasterias & 223 & Hilir \\
\hline 12. & Cosmarium & 44 & Hilir \\
\hline 13. & Spirogyra & 223 & Tengah dan hilir \\
\hline 14. & Xantidium & 178 & Hilir \\
\hline 15. & Coscinodiscus & 355 & Hulu, tengah, dan hilir \\
\hline 16. & Micractinium & 133 & Hulu dan tengah \\
\hline 17. & Closteriopsis & 133 & Tengah \\
\hline \multicolumn{4}{|c|}{ III. Cyanophyceae } \\
\hline 1. & Oscillatoria & 578 & Hulu, tengah, dan hilir \\
\hline \multicolumn{4}{|c|}{ IV. Euglenaphyceae } \\
\hline 1. & Euglena & 133 & Hulu dan tengah \\
\hline 2. & Lemnnea & 178 & Tengah dan hilir \\
\hline \multicolumn{4}{|c|}{ B. Zooplankton } \\
\hline \multicolumn{4}{|c|}{ I. Rotifera } \\
\hline 1. & Brachionus & 312 & Tengah dan hilir \\
\hline 2. & Euchlanis & 88 & Tengah dan hilir \\
\hline \multicolumn{4}{|c|}{ II. Copepoda } \\
\hline 1. & Nauplius & 400 & Tengah dan hilir \\
\hline
\end{tabular}


Tabel 2. Jenis-jenis plankton yang teridentifikasi di perairan Sungai Musi, bulan Juli 2002 (sel per ind. perl)

\begin{tabular}{|c|c|c|c|}
\hline No. & Jenis plankton & Jumlah sel per ind. per I & Daerah penyebare \\
\hline \multicolumn{4}{|c|}{ A. Phytoplankton } \\
\hline \multicolumn{4}{|c|}{ I. Bacillariophyceae } \\
\hline 1. & Diatoma & 88 & Hulu dan tengah \\
\hline 2. & Surirella & 488 & Hulu, tengah, dan hilir \\
\hline 3. & Gyrosigma & 44 & Hulu \\
\hline 4. & Stephanodiscus & 133 & Hulu, tengah, dan hilir \\
\hline 5. & Synedra & 444 & Hulu, tengah, dan hilir \\
\hline 6. & Tabellaria & 622 & Hulu, tengah, dan hilir \\
\hline 7. & Fragillaria & 177 & Hulu dan tengah \\
\hline 8. & Melosira & 88 & Tengah \\
\hline 9. & Navicula & 88 & Tengah \\
\hline 10. & Cyclotella & 177 & Tengah dan hilir \\
\hline \multicolumn{4}{|c|}{ II. Chlorophyceae } \\
\hline 1. & Volvox & 177 & Hulu, tengah, dan hilir \\
\hline 2. & Clostrerium & 488 & Hulu, tengah, dan hilir \\
\hline 3. & Raphidium & 533 & Hulu, tengah, dan hilir \\
\hline 4. & Ulotrix & 355 & Hulu, tengah, dan hilir \\
\hline 5. & Pediastrum & 355 & Hulu, tengah, dan hilir \\
\hline 6. & Spiroghyra & 233 & Hulu, tengah, dan hilir \\
\hline 7. & Zygnema & 44 & Tengah \\
\hline 8. & Micrasterias & 133 & Tengah dan hilir \\
\hline 9. & Chlorococcum & 312 & Tengah dan hilir \\
\hline 10. & Stigeoclonium & 44 & Tengah \\
\hline 11. & Cosmarium & 88 & Tengah \\
\hline 12. & Staurastrum & 133 & Tengah dan hilir \\
\hline 13. & Chlorella & 88 & Tengah \\
\hline 14. & Sphaerocystis & 177 & Tengah dan hilir \\
\hline 15. & Drapnaldia & 44 & Tengah \\
\hline 16. & Coscinodiscus & 133 & Tengah dan hilir \\
\hline 17. & Ankistrodesmus & 44 & Hilir \\
\hline 18. & Xanthidium & 88 & Tengah dan hilir \\
\hline 19. & Ghomposphaeria & 88 & Hulu dan tengah \\
\hline 20. & Hydrodyctium & 44 & Hilir \\
\hline 21. & Actinastrum & 44 & Hilir \\
\hline 22. & Treubaria & 44 & Tengah \\
\hline 23. & Ghomphonema & 44 & Hulu \\
\hline 24. & Gonatozygon & 44 & Hilir \\
\hline \multicolumn{4}{|c|}{ III. Cyanophyceae } \\
\hline 1. & Lyngbya & 88 & Tengah \\
\hline 2. & Spirulina & 88 & Hulu, tengah, dan hilir \\
\hline 3. & Oscillatoria & 266 & Tengah dan hilir \\
\hline 4. & Anabaena & 88 & Hilir \\
\hline 5. & Arthrodesmus & 44 & Tengah \\
\hline 6. & Phormidium & 44 & Tengah \\
\hline 7. & Tolypothrix & 44 & Tengah \\
\hline 8. & Merismopodia & 44 & Hilir \\
\hline \multicolumn{4}{|c|}{ IV. Rhodophyceae } \\
\hline 1. & Testudinella & 44 & Tengah \\
\hline V. E & $\begin{array}{l}\text { Lemnea } \\
\text { lenophyceae }\end{array}$ & 44 & Tengah \\
\hline 1. & Euglena & 178 & Tengah dan hilir \\
\hline \multicolumn{4}{|c|}{ VI. XANTROPHYCEAE } \\
\hline 1. & Uroglenopsis & 44 & Hulu \\
\hline
\end{tabular}


Tabel 2. Lanjutan

\begin{tabular}{|c|c|c|c|}
\hline No. & Jenis plankton & Jumlah sel per ind. per I & Daerah penyebarar \\
\hline \multicolumn{4}{|c|}{ B. Zooplankton } \\
\hline \multicolumn{4}{|c|}{ I. Rotifera } \\
\hline 1. & Notholca & 44 & Tengah \\
\hline 2. & Brachionus & 233 & Tengah dan hilir \\
\hline 3. & Monostyla & 355 & Tengah dan hilir \\
\hline 4. & Euchlanis & 88 & Tengah dan hilir \\
\hline 5. & Chromogaster & 44 & Hilir \\
\hline 6. & Keratella & 44 & Hilir \\
\hline 7. & Ramate Jaws & 44 & Tengah \\
\hline 8. & Tricochera & 44 & Tengah \\
\hline \multicolumn{4}{|c|}{ II. Copepoda } \\
\hline 1. & Bosmin & 44 & Tengah \\
\hline 2. & Nauplius & 233 & Tengah dan hilir \\
\hline 3. & Eubranchipus & 44 & Hulu \\
\hline 4. & Cyclops & 44 & Hilir \\
\hline
\end{tabular}


Tabel 3. Jenis-Jenis plankton yang teridentifikasi di perairan Sungai Musi, bulan September 2002 (sel per ind. per I)

\begin{tabular}{|c|c|c|c|}
\hline No. & Jenis plankton & Jumlah sel per ind. per I & Daerah penyebaran \\
\hline \multicolumn{4}{|c|}{ A. Phytoplankton } \\
\hline \multicolumn{4}{|c|}{ I. Bacillariophyceae } \\
\hline 1. & Diatoma & 400 & Hulu, tengah, dan hilir \\
\hline 2. & Gyrosigma & 88 & Hulu dan tengah \\
\hline 3. & Melosira & 88 & Hulu \\
\hline 4. & Surirela & 400 & Hul, tengah, dan hilir \\
\hline 5. & Synedra & 44 & Hulu \\
\hline 6. & Tabellaria & 88 & Hulu dan tengah \\
\hline 7. & Cylotella & 178 & Tengah dan hilir \\
\hline \multicolumn{4}{|c|}{ II. Chlorophyceae } \\
\hline 1. & Ulotrix & 488 & Hulu, tengah, dan hilir \\
\hline 2. & Closterium & 444 & Hulu, tengah, dan hilir \\
\hline 3. & Spyrogyra & 233 & Hulu dan hilir \\
\hline 4. & Ankistrodesmus & 88 & Hulu \\
\hline 5. & Raphidium & 88 & Hulu dan hilir \\
\hline 6. & Stigeoclonium & 44 & Hulu \\
\hline 7. & Cholorococcum & 488 & Hulu, tengah, dan hilir \\
\hline 8. & Micrasterias & 178 & Hulu, tengah, dan hilir \\
\hline 9. & Mougeotia & 44 & Tengah \\
\hline 10. & Sphaerocystis & 444 & Tengah dan hilir \\
\hline 11. & Staurastrum & 178 & Tengah dan hilir \\
\hline 12. & Scenedesmus & 88 & Tengah \\
\hline 13. & Pediasetrum & 400 & Hulu, tengah, dan hilir \\
\hline 14. & Xanthidium & 133 & Hulu dan tengah \\
\hline 15. & Actinastrum & 133 & Tengah dan hilir \\
\hline 16. & Microspora & 44 & Tengah dan hilir \\
\hline 17. & Coscinodiscus & 312 & Hilir \\
\hline \multicolumn{4}{|c|}{ III. Cyanophyceae } \\
\hline 1. & Anabaena & 178 & Hulu dan hilir \\
\hline 2. & Lyngbya & 88 & Hulu dan hilir \\
\hline 3. & Oscillatoria & 312 & Tengah dan hilir \\
\hline 4. & Spirulina & 44 & Hilir \\
\hline \multicolumn{4}{|c|}{ IV. Rhodophyceae } \\
\hline 1. & Lemnea & 44 & Hulu \\
\hline \multicolumn{4}{|c|}{ B. Zooplankton } \\
\hline \multicolumn{4}{|c|}{ I. Rotifera } \\
\hline 1. & Brachionus & 400 & Tengah dan hilir \\
\hline 2. & Karatella & 178 & Tengah dan hilir \\
\hline 3. & Polyarthra & 133 & Tengah dan hilir \\
\hline 4. & Monostyla & 44 & Tengah \\
\hline \multicolumn{4}{|c|}{ II. Copepoda } \\
\hline 1. & Cylops & 44 & Hilir \\
\hline 2. & Nauplius & 233 & Hilir \\
\hline \multicolumn{4}{|c|}{ III. Cladocera } \\
\hline 1. & Moina & 266 & Tengah dan hilir \\
\hline
\end{tabular}


Tabel 4. Jenis-jenis plankton yang teridentifikasi di perairan Sungai Musi, bulan Nopember 2002 (sel per ind. perl)

\begin{tabular}{|c|c|c|c|}
\hline No. & Jenis plankton & Jumlah sel per ind. per I & Daerah penyebaran \\
\hline \multicolumn{4}{|c|}{ A. Phytoplankton } \\
\hline \multicolumn{4}{|c|}{ I. Bacillariophyceae } \\
\hline 1. & Diatoma & 533 & Hulu, tengah, dan hilir \\
\hline 2. & Gyrosigma & 266 & Hulu, tengah, dan hilir \\
\hline 3. & Melosira & 88 & Hulu dan tengah \\
\hline 4. & Surirella & 533 & Hulu, tengah, dan hilir \\
\hline 5. & Tabellaria & 178 & Hilir \\
\hline \multicolumn{4}{|c|}{ II. Chlorophyceae } \\
\hline 1. & Ulotrix & 666 & Hulu, tengah, dan hilir \\
\hline 2. & Closterium & 88 & Tengah \\
\hline 3. & Spirogyra & 178 & Hilir \\
\hline 4. & Ankistrodesmus & 88 & Tengah dan hilir \\
\hline 5. & Raphidium & 178 & Hulu dan tengah \\
\hline 6. & Chlorococcum & 312 & Hilir \\
\hline 7. & Micrasterias & 133 & Hulu dan tengah \\
\hline 8. & Sphaerocystis & 88 & Tengah \\
\hline 9. & Scenedesmus & 44 & Hulu \\
\hline 10. & Pediastrum & 133 & Tengah dan hilir \\
\hline 11. & Xanthidium & 88 & Hilir \\
\hline 12. & Actinastrum & 44 & Tengah \\
\hline 13. & Microspora & 88 & Tengah \\
\hline 14. & Terpsinoe & 133 & Hulu dan tengah \\
\hline 15. & Volvox & 44 & Hilir \\
\hline & Coscinodiscus & 178 & Hilir \\
\hline \multicolumn{4}{|c|}{ III. Cyanophyceae } \\
\hline 1. & Gompospharea & 133 & Hilir \\
\hline 2. & Anabaena & 44 & Hilir \\
\hline 3. & Lyngbya & 88 & Tengah dan hilir \\
\hline \multicolumn{4}{|c|}{ B. Zooplankton } \\
\hline \multicolumn{4}{|c|}{ I. Rotifera } \\
\hline 1. & Bosmina & 88 & Tengah dan hilir \\
\hline 2. & Euchlanis & 44 & Hilir \\
\hline 3. & Brachionus & 355 & Hulu dan hlir \\
\hline 4. & Keratella & 88 & Hilir \\
\hline 5. & Polyarthra & 178 & Tengah dan hilir \\
\hline 6. & Monostyla & 88 & Hulu dan tengah \\
\hline 7. & Ceromogaster & 44 & Tengah \\
\hline \multicolumn{4}{|c|}{ II. Copepoda } \\
\hline 1. & Cylops & 233 & Hilir \\
\hline 2. & Nauplius & 488 & Hulu, tengah, dan hilir \\
\hline
\end{tabular}

\section{KESIMPULAN}

1. Plankton dari kelas Bacillariophyceae dan Chlorophyceae mempunyai jumlah jenis yang lebih banyak dibandingkan dengan yang lain seperti dari kelas Cyanophyceae, Rhodophyceae, Euglenophyceae, dan Xantrophyceae.

2. Zooplankton dari kelas Rotifera lebih banyak dari kelas yang lain seperti dari kelas Copepoda dan Cladocera.

\section{DAFTAR PUSTAKA}

APHA.1981. Standart method for the examination of water and wastewater. $15^{\text {th }}$ Edition. American Piblic health Association. Washington. D. C. 1.134 p.

Pennak, R. W. 1978. Freshwater invertebrate in the United State of America. Mc. Grawhill Book Company. Welcome. R. L. 1979. Fisheries Ecology of Floodplain River. Longman. London. 317 p.

Wetzel, R. G. 1975. Limnology. Sounders Colledgee Publishing. West Washington Square. Philadelphia. $743 p$. 